Artículo

\title{
Aceleração e autotraição: além do tempo livre e da questão distributiva
}

\author{
Aceleración y auto-traición. Más allá del tiempo libre y la cuestión distributiva
}

\section{Acceleration and Self-Betrayal. Beyond Leisure Time and the Distributive Issue}

Mauro Basaure *

* UNIVERSIDAD ANDRÉS BELLO

\section{Resumo:}

A obra de Rosa pode ser reconstruída, em grande medida, como uma pesquisa acerca das causas da aceleração, do esclarecimento fenomenológico desse fenômeno complexo e da análise crítica das suas consequências. Seguindo essa intuição, este artigo delimita e reconstrói parte importante dessa obra, buscando conectar o fenômeno da aceleração com uma das suas principais consequências, a saber: a discrepância entre as orientações de valor, por um lado, e as ações reais, por outro, processo que Rosa associa ao fenômeno da alienação. Por que as pessoas fazem coisas que não desejam fazer, que não coincidem com suas orientações de valor? Esta pergunta torna-se crucial para conectar teoria crítica e sociologia empírica, ou, em outras palavras, o estudo das patologias sociais do tempo e da aceleração com questões relativas às injustiças sociais.

Palavras-chave: Aceleração social; Hartmut Rosa; Tempo livre; Alienação; Autotraição

\section{Resumen:}

La obra de Rosa se deja reconstruir, en gran medida, en términos de una búsqueda de las causas de la aceleración, de la clarificación fenomenológica de este complejo fenómeno, así como del análisis crítico de sus consecuencias. Siguiendo esta intuición, este artículo delimita y reconstruye parte importante de dicha obra, tratando de conectar el fenómeno de la aceleración 
con una de sus consecuencias: la discrepancia entre orientaciones de valor, por una parte, y acciones reales, por la otra, cuestión que Rosa asocia con el fenómeno de la alienación. ¿Por qué las personas hacen cosas que no desean hacer, que no coinciden con sus orientaciones de valor? Esta pregunta resulta clave para conectar teoría crítica y sociología empírica, es decir, el estudio de las patologías sociales del tiempo y la aceleración con cuestiones relativas a las injusticias.

Palabras clave: Aceleración social; Hartmut Rosa; Tiempo libre; Alienación; Auto-traición.

\begin{abstract}
:
To a large extent, Rosa's work can be reconstructed in terms of a searching for the causes of acceleration and the phenomenological clarification of such complex phenomena, as well as a critical analysis of its consequences. Following this intuition, the article provides a reconstructive framework of Rosa's work, connecting the acceleration phenomena with one of its consequences: the discrepancies between value orientations, on the one hand, and actual actions, on the other - a question associated by Rosa with the phenomena of alienation. Why do people act in ways they don't wish, which diverge from their value orientations? This question remains key to connecting critical theory and empirical sociology, that is, the study of social pathologies of time and acceleration with issues related to injustices.
\end{abstract}

Keywords: Social Acceleration, Hartmut Rosa, Leisure Time, Alienation, Self-Betrayal.

Recebido: 5 de outubro de 2020.

Aceitaram: 15 de dezembro de 2020. 


\section{Introdução}

A obra do sociólogo e filósofo alemão Hartmut Rosa tem suscitado muito interesse desde a publicação do seu livro Beschleunigung. Die Veränderung der Zeitstrukturen in der Moderne (Aceleração: a transformação das estruturas temporais na modernidade) ${ }^{1}$ em 2005. Se este livro já situava Rosa em uma perspectiva própria da teoria crítica, no seu segundo grande livro fica ainda mais marcado seu pertencimento a essa corrente, dado que constitui um claro esforço por renovar, visando a uma sociologia de nossas relações com o mundo, o conceito de alienação, talvez a noção mais característica da teoria crítica. Trata-se do livro Resonanz: Eine Soziologie der Weltbeziehung (Ressonância: uma sociologia da relação com o mundo), publicado em $2016^{2}$.

Qual é a relação entre essas duas obras? Ou melhor dizendo, qual é a relação entre o fenômeno da aceleração e a questão da ressonância, relação a qual constitui, por sua vez, a interface da alienação? O próprio Rosa deu início a esta tarefa em um livro de menor extensão intitulado Beschleunigung und Entfremdung, e vários pesquisadores têm trabalhado essa conexão, explorando as várias formas possíveis de estabelecê-la. Tanto Rosa quanto as pesquisas acerca do seu trabalho têm mostrado com clareza que ambas as noções se vinculam na forma de uma teoria crítica que denuncia as consequências negativas da aceleração para a nossa relação com o mundo.

Dentro deste quadro, além da reconstrução da teoria de Rosa, com o objetivo de delimitá-la e expor seus aspectos essenciais, neste artigo meu interesse é destacar como ele identifica na aceleração, dinamizada por sua vez pelo crescimento, as fontes da discrepância sistemática entre o que as pessoas fazem e o que desejariam fazer. Trata-se de um fenômeno que Rosa entende como uma forma de alienação ou - utilizando o conceito que ele propõe como oposto - de bloqueio da ressonância. Este ponto me parece especialmente pertinente para

\footnotetext{
${ }^{1}$ Hartmut Rosa, Beschleunigung: Die Veränderung der Zeitstrukturen in der Moderne: 1760 (Frankfurt am Main: Suhrkamp, 2005). Traduzido para o inglês como Social Acceleration: A New Theory of Modernity em 1995; até o momento não foi traduzido para o castelhano.

2 Hartmut Rosa, Resonanz: Eine Soziologie der Weltbeziehung (Berlin: Suhrkamp, 2018). Traduzido para o castelhano em 2019 sob o título Resonancia: Una sociología de la relación con el mundo.

${ }^{3}$ Hartmut Rosa, Beschleunigung und Entfremdung: Entwurf einer kritischen Theorie spätmoderner Zeitlichkeit (Berlin: Suhrkamp, 2013). Tem tradução para o castelhano sob o título Aceleración y Alienación. Esbozo de una teoría crítica de la temporalidad de la modernidad tardía.
} 
conectar a teoria crítica de Rosa com os estudos empíricos sobre o tempo. Em linhas gerais, começo localizando a obra de Rosa no entrecruzamento entre diagnóstico do presente, teoria crítica das patologias sociais e teoria sociológica, para em seguida estabelecer os limites de tal teoria - não no sentido das suas deficiências e sim no que concerne à sua delimitação e ao contexto em que poderia ser aplicada. Embora existam várias perspectivas sociológicas acerca da aceleração das sociedades modernas ${ }^{4}$, uma das características distintivas da teoria de Rosa é a sua concepção do processo de aceleração nos termos de três dimensões independentes, mas em interação: aceleração tecnológica, aceleração das mudanças sociais e aceleração do ritmo da vida. Em um segundo passo, esta teoria enfatiza a dimensão do ritmo da vida e, particularmente, sua relação com o tempo livre. Além disso, ressalto como a perspectiva de Rosa se diferencia da sociologia a respeito do uso do tempo, embora em certos pontos possam ocorrer interfaces. Uma vez abordadas essas questões, centro-me naquele ponto que trata de esclarecer uma relação distorcida com nós mesmos, em particular na medida em que as condições geradas pela aceleração conduzem à contradição no âmbito das avaliações fortes: por um lado, afirmamos certos valores discursivamente como definidores da nossa identidade, da nossa maneira de viver, dos nossos desejos; por outro, realizamos ações concretas compelidas pela aceleração. Dessa maneira é possível falar de uma autotraição, no sentido de que as pessoas não conseguem realizar-se no seu agir - sem dúvidas, tal questão lembra uma das dimensões da alienação que, mesmo em um contexto distinto, já era identificada por Marx.

\section{Delimitações da crítica das sociedades da modernidade tardia em chave temporal}

Assumindo uma perspectiva heterodoxa em relação às leituras tradicionais sobre os clássicos da sociologia, Rosa argumenta que Marx, Weber, Durkheim e Simmel estavam atentos ao fenômeno

\footnotetext{
${ }^{4}$ Compilação de textos clássicos e contemporâneos sobre a aceleração que se encontra em Hartmut Rosa y William E Scheuerman eds., High-Speed Society: Social Acceleration, Power, and Modernity (Pennsylvania: Pennsylvania State University Press, 2010).
} 
da aceleração ${ }^{5}$. Contudo, apesar da sua relevância, a aceleração não chegou a constituir-se como uma dimensão-chave da análise sociológica - tal como ocorreu com os conceitos de racionalização, diferenciação ou individualização -, o que resultou na falta de desenvolvimento conceitual e empírico acerca desse fenômeno no interior das ciências sociais e da sociologia. Segundo essa leitura, o estudo das sociedades modernas não teria encontrado novidade alguma no que diz respeito à questão da aceleração. No entanto, apesar dessa tradição deficitária, trata-se hoje de um campo de estudo da sociologia que se encontra em plena expansão e que tem em Rosa um dos seus mais destacados pesquisadores.

Com efeito, a teoria da aceleração social de Rosa se transformou num dos principais diagnósticos do tempo presente formulados na última década. Essa teoria descreve a sociedade da modernidade tardia e concorre, assim, com diagnósticos que a classificam de maneiras distintas como sociedade: do risco, do serviço, da informação nas redes, do medo, da vivência (Erlebnis), do cansaço, entre outras. Embora não conste no título, de fato nos seus livros Rosa faz um uso reiterado da noção de "sociedade da aceleração". Na construção do seu próprio diagnóstico, Rosa recorre a estudos que há décadas já haviam acentuado a aceleração enquanto descrição da sociedade atual, a fim de dialogar proveitosamente com vários outros diagnósticos do presente mencionados.

No entanto, Rosa tem uma ambição que vai além da descrição sociológica e dos diagnósticos do tempo presente. Seu esforço por situar-se na tradição da teoria crítica da sociedade é visível, daí que ele estabeleça um diálogo com a tradição da escola de Frankfurt e busque inserir a noção marxista clássica de alienação numa análise sobre como o fenômeno da aceleração distorce sistematicamente as relações entre o indivíduo e o mundo - questão que, embora anunciada timidamente no seu livro sobre aceleração ${ }^{6}$, foi explicitamente desenvolvida

\footnotetext{
${ }^{5}$ Hartmut Rosa fez contribuições importantes ao conhecimento e divulgação da teoria sociológica. Conferir Hartmut Rosa, David Strecker e Andrea Kottmann, Soziologische Theorien. Stuttgart: UTB Basics, 2018.

${ }^{6}$ Hartmut Rosa, “On Defining the Good Life: Liberal Freedom and Capitalist Necessity”. Constellations 5 (1998): 201-14.
} 
primeiro no seu estudo sobre alienação ${ }^{7}$ e, depois, no livro sobre ressonância ${ }^{8}$, no qual se propõe este conceito como referente normativo para a possibilidade de uma sociedade pós-crescimento ${ }^{9}$.

Isso inscreve o seu diagnóstico mais no campo de uma crítica das patologias sociais do que no de uma teoria crítica das injustiças. Sua perspectiva centra foco no fenômeno da aceleração, na explicação das suas causas e no reconhecimento e na crítica dos seus efeitos, e não apenas na pergunta acerca do "como" desse fenômeno - por exemplo, como ele afeta desigualmente vários grupos sociais. Para Rosa, a crítica da sociedade capitalista não deveria ter seu eixo nem em contradições econômicas imanentes, nem em seus problemas funcionais, e tampouco nos problemas de justiça social - seja em perspectiva de redistribuição ou de reconhecimento ${ }^{10}-$, senão num problema fundamental de ordem ética: quanto mais eficaz é o seu funcionamento, maior é a imposição compulsiva de exigências que conduziriam a uma espiral sem fim e cega, em que o indivíduo, especialmente aquele integrado ao sistema, trairia os seus próprios ideais de boa vida ${ }^{11}$.

De fato, o fenômeno da aceleração e as suas consequências alienadoras podem ser interrogados desde uma perspectiva ética por se tratarem de patologias da sociedade moderna; torna-se, porém, difícil afirmar que estas constituam injustiças. Além disso, a descrição de Rosa, devido a sua construção argumentativa e retórica, impacta de maneira tal que consegue produzir uma reflexão crítica acerca da nossa práxis tanto individual quanto institucional ${ }^{12}$. Nesse sentido, Leccardi (2003) buscou identificar as linhas de resistência dos processos de aceleração, levando em consideração a relevância de não refletir separadamente sobre eles ${ }^{13}$. Como um modo de levar adiante a crítica das patologias sociais, este gênero insere-se em um tipo de crítica que

\footnotetext{
${ }^{7}$ Rosa, Beschleunigung und Entfremdung.

${ }^{8}$ Rosa, Resonanz.

${ }^{9}$ Hartmut Rosa, Unverfügbarkeit (Salzburgo: Residenz, 2018), “'Spirituelle Abhängigkeitserklärung'. Die Idee des Mediopassiv als Ausgangspunkt einer radikalen Transformation”, em Große Transformation? Zur Zukunft moderner Gesellschaften: Sonderband des Berliner Journals für Soziologiei, Klaus Dörre, Hartmut Rosa, Karina Becker, Sophie Bose e Benjamin Seyd eds., 35-56 (Wiesbaden: VS Verlag für Sozialwissenschaften, 2019).

${ }^{10}$ Axel Honneth, "Umverteilung als Anerkennung. Eine Erwiderung auf Nancy Fraser", en Umverteilung oder Anerkennung? Eine politisch-philosophische Kontroverse, 129-224 (Frankfurt am Main: Suhrkamp, 2003).

${ }^{11}$ Hartmut Rosa, "Capitalism as a Spiral of Dynamisation: Sociology as Social Critique", em Sociology, Capitalism, Critique, Hartmut Rosa, Stephan Lessenich e Klaus Dörre eds., 67-97 (London: Verso, 2015).

${ }^{12}$ Dois exemplos: o recurso à frase "correr mais rápido para estar sempre no mesmo lugar", cuja melhor metáfora é o auge das academias e suas esteiras, o workout; ou a interpretação de parte importante da indústria em expansão, associada a tempos de férias, relaxamento, etc., se conhece como "Oásis de desaceleração".

${ }^{13}$ Carmen Leccardi, "Resisting 'Acceleration Society”, Constellations 10 (2003): 34-41.
} 
funciona alertando e gerando mudanças de consciência, desnaturalizando nosso cotidiano, um pouco da forma em que Foucault descreveu as instituições modernas.

Embora o ponto sociológico das injustiças não esteja completamente fora do radar das análises de $\mathrm{Rosa}^{14}$, claramente tem menos centralidade que seu diagnóstico global. Nesta diferença entre patologia e injustiça se reconhece a distinção entre a perspectiva de Rosa e a sociologia embasada em estudos empíricos do tempo. As análises de Rosa supõem um diagnóstico sócio-histórico no nível de processos de desinstitucionalização das sociedades modernas, nas quais é cada vez mais nítida a ruptura do vínculo entre o tempo cronológico (quando e quanto tempo), o local (onde) e o tipo de atividades (o quê) - por exemplo, no que diz respeito à divisão entre tempo de trabalho e tempo livre. Entretanto, todos esses vínculos supõem estruturalmente os estudos empíricos do uso do tempo. A partir dessa constatação decorrem conclusões interessantes acerca das condições sociais da constituição das identidades sociais e políticas - por exemplo, a dos operários, que estão na base das teorias sobre lutas sociais tais como as do reconhecimento ${ }^{15}$.

Se essa distinção entre patologias e injustiças permite delimitar a perspectiva de Rosa, também ajuda a reconhecer o tipo de sociedade que ele tem em vista. A referência aos clássicos da sociologia não deve confundir: embora o fenômeno da aceleração possa ser rastreado desde o início da sociedade industrial moderna - que é a sociedade dos clássicos da sociologia -, também é certo que a aceleração social, tal como estudada por Rosa, é um conceito que diz respeito a um fenômeno que caracteriza de maneira fundamental a modernidade e o capitalismo tardios ${ }^{16}$. Isto não seria válido não apenas diacronicamente, mas também de modo sincrônico: a teoria de Rosa cabe melhor às sociedades modernas capitalistas com alto desenvolvimento do que àquelas com

\footnotetext{
${ }^{14}$ Ver por exemplo sua intervenção no debate sobre redistribuição e reconhecimento, em Hartmut Rosa, "(Parity of) Participation-The Missing Link Between Resources and Resonance", em Feminism, Capitalism, and Critique: Essays in Honor of Nancy Fraser, Banu Bargu y Chiara Bottici eds., 157-66 (New York: Palgrave Macmillian, 2017).

${ }^{15}$ Rosa diagnostica uma transformação das lutas pelo reconhecimento. Em seu novo tipo, estas são basicamente individuais: lutar por posições de privilégio que fornecem valor social. Tais lutas não seriam contrárias a determinadas formações sociais, já que teriam lugar no interior da própria sociedade, sem pretender mudá-la. Ver Hartmut Rosa, "Von der stabilen Position zur dynamischen Performanz Beschleunigung und Anerkennung in der Spätmoderne", en Sozialphilosophie und Kritik, Rainer Forst, Martin Hartmann, Rahel Jaeggi y Martin Saar eds., 655-71 (Frankfurt am Main: Suhrkamp, 2009).

${ }^{16}$ Em inglês, seu livro sobre a aceleração se intitula como "Nova teoria da modernidade" (Rosa, Beschleunigung). Entretanto, o subtítulo da obra acerca da alienação e aceleração é "Esboço de uma teoria crítica da temporalidade na modernidade tardia" (Rosa, Beschleunigung und Entfremdung).
} 
menor. Efetivamente, dando os créditos a $\operatorname{Linder}^{17}$, que estabeleceu uma relação entre os níveis de bem-estar e disponibilidade de tempo (quanto maior o bem-estar, maior a escassez do tempo), Rosa também concebe essa relação no que diz respeito ao fenômeno da aceleração. Nem todas as sociedades modernas são igualmente aceleradas; isso teria relação com o nível de desenvolvimento, bem-estar financeiro e penetração do capitalismo nas diferentes esferas sociais. Com relação a este último, os regimes de bem-estar podem ser definidos em termos de uma institucionalidade que busca explorar determinados serviços, entendidos como básicos na lógica da competência, e que seria um dos motores-chave da aceleração. Para Rosa, tal perspectiva explica por que a competição se intensifica quando esses regimes de bem-estar ou de segurança social são desmontados, já que começa a abranger o espaço de ação para conseguir privadamente os serviços antes providos pela sociedade e pelo Estado.

O expressado acima concerne em grandes linhas o nível macro no qual opera a teoria de Rosa. No entanto, não deve ser esquecido que o que está em jogo são os indivíduos e as suas experiências. Em função disso, é possível identificar uma outra delimitação dessa teoria: na medida em que a aceleração é concebida como mais uma das características do processo de modernização capitalista, quem estiver de fora ou excluído dele também estaria fora do diagnóstico de Rosa. Esta teoria não faz sentido algum para grupos tais como: desempregados, aposentados ou os chamados "Ninis" 18 , entre outros, uma lista em que deveria considerar as pessoas que moram em regiões com baixo nível de modernização, muitas das quais, de fato, têm fugido ou migrado da vida acelerada das grandes cidades. Assim, se reforça o desenvolvido acima, isto é, o fato de esta ser uma teoria menos ajustada às questões de justiça (que sempre pressupõem uma referência a grupos particulares) do que a questões globais que a princípio não envolvem a todos, mas sim a qualquer um.

Finalmente, um limite importante se vincula ao fato de que Rosa reconhece, dentro dos processos de alta modernização, que o fenômeno da aceleração coexiste com a não-aceleração e até com processos de desaceleração, sendo isso um produto simultâneo e indireto da própria aceleração (como os problemas de mobilidade nas grandes cidades). A aceleração é a variação da

\footnotetext{
${ }^{17}$ Staffan Burenstam Linder, The Harried Leisure Class (New York: Columbia University Press, 1970).

${ }^{18}$ Palavra espanhola para descrever uma geração jovem, rebelde e global interessada apenas em festas, sem trabalho ou estudo [Nota do Tradutor].
} 
velocidade em um intervalo de tempo. Portanto, mesmo que a velocidade seja alta, enquanto esta se mantiver constante não há aceleração. Isso conduz à diferenciação das consequências da aceleração com respeito a uma sociedade que já seja veloz em si mesma e a introdução de maiores diferenças nas análises empíricas. A tese de Rosa é que as sociedades capitalistas da modernidade tardia, em geral, operam em alta velocidade e frequentemente padecem de processos de aceleração, só que estes não seriam permanentes, ou seja, seria errado concebê-los como constantes e lineares. De fato, Rosa identifica duas grandes ondas de aceleração, uma no começo do século XX e outra por volta de 1970: a primeira como consequência da massiva revolução industrial, e a segunda por conta das crescentes inovações microeletrônicas e digitais.

\section{As acelerações, seus vínculos e motores}

Outra determinação importante da teoria de Rosa parte da base que a aceleração tem múltiplas manifestações não redutíveis entre si. Ele busca colocá-las dentro de uma proposta analítica que abrange três processos: a aceleração tecnológica, a aceleração da mudança social e a aceleração do ritmo da vida ${ }^{19}$. Ulferts, Korunka y Kubicek têm confirmado esta estrutura tripartite da aceleração por meio de uma pesquisa sobre demandas de tempo em um grupo de trabalhadores ${ }^{20}$. Apesar disso, há muito ainda a ser pesquisado empiricamente nessa área, pois, mesmo respondendo a tal ideia ou meta-conceito - já que trata, em cada caso, do crescimento quantitativo por unidade de tempo ${ }^{21}$-, tal diversidade interna torna equivocada a compreensão da aceleração como um único macroprocesso.

A aceleração tecnológica é definida como o incremento da produção total por unidade de tempo. Exemplos disso são: os quilômetros percorridos em uma hora, os bytes transferidos por cada segundo, as mercadorias produzidas por dia. Trata-se da inegável velocidade adquirida por aqueles processos orientados a atingir metas específicas nas áreas do transporte, da comunicação e da produção. Essa aceleração transforma a relação tempo/espaço, aproxima o distante, abre

\footnotetext{
${ }^{19}$ Rosa, Beschleunigung.

${ }^{20}$ Heike Ulferts, Christian Korunka e Bettina Kubicek, "Acceleration in working life: An empirical test of a sociological framework", Time \& Society 22 (2013): 161-185.

${ }^{21}$ Rosa, Beschleunigung.
} 
possibilidades antes inusitadas ou torna simultâneas coisas que não o são ${ }^{22}$. $\mathrm{Na}$ internet tudo ocorre em toda parte ao mesmo tempo.

Se a aceleração tecnológica se refere aos fenômenos de aceleração que ocorrem no interior da sociedade, a aceleração das mudanças sociais se refere à aceleração da sociedade mesma, quer dizer, da sua própria dinâmica de mudanças. Em diálogo com Koselleck, Rosa argumenta que a velocidade da mudança é que é incrementada (acelerada). Sem dúvida, todas as sociedades mudam; entretanto, o distintivo é que isso ocorre de modo mais veloz e acelerado. Tais mudanças quantitativas acarretam efeitos qualitativos, sendo o mais importante aquele que Rosa, seguindo o filósofo Hermann Lübbe (2009), chama de "contração do presente", referindo-se à contração dos lapsos de tempo que se definem como presente. $\mathrm{O}$ atual ou o presente torna-se cada vez mais efêmero e acaba com maior rapidez. Para o sujeito, tal fato se traduz na crescente obsolescência do seu know-how, seus conhecimentos e práticas voltadas ao que tem valor $^{23}$. Em consequência, na contração há uma perda de confiança na própria experiência acumulada e nas expectativas do futuro. $\mathrm{O}$ modo de adaptação a essa contração, como será observado mais adiante, supõe a capacidade de "reinventar-se" e atualizar-se repetidas vezes para deparar-se com contextos em permanente mudança.

Por sua vez, Rosa define a aceleração do ritmo da vida como um incremento do número de episódios de ação ou experiência por unidade de tempo. Este aumento é consequência do desejo ou necessidade sentida pelos sujeitos de fazer mais coisas em menos tempo. Portanto, será relevante para Rosa responder o porquê desses desejos ou o porquê da necessidade de fazer mais em menos tempo. Prévio à compreensão deste ponto, Rosa centra-se em mostrar como se manifesta esse modo específico de aceleração, propondo diferenciar uma dimensão subjetiva de uma objetiva. Assim, a teoria de Rosa pode dialogar com e alimentar-se de dados produzidos nas pesquisas sociológicas sobre o tempo - especialmente aquelas que incorporaram a dimensão de percepção subjetiva, mas também aquelas tradicionais que permitem mensurar e comparar as quantidades de tempo empenhadas em atividades cotidianas.

\footnotetext{
${ }^{22}$ Ralf Beuthan, "Media and Time", em Encyclopedia of Time: Science, Philosophy, Theology, \& Culture, H. James Birx ed., 832-41 (Los Angeles: SAGE Publications, 2009).

${ }^{23}$ Boltanski e Esquerre, pelo contrário, identificaram um modo em que a temporalidade e o capitalismo se aliaram para a produção de certos objetos. Luc Boltanski y Arnaud Esquerre, Enrichissement. Une critique de la marchandise (Paris: Editions Gallimard, 2017).
} 
A dimensão subjetiva é observável no fato, já demonstrado em pesquisas sobre o tempo, de que os indivíduos crescentemente experimentam o tempo como escasso. Eles se sentem pressionados pela falta dele, com a sensação de que tudo anda muito rápido e que não se consegue nem acompanhar as mudanças nem estar atualizado, aliás, muitas das vezes com manifesto estresse. Por outra parte, usando a noção de "contração", haveria duas formas de avaliar a dimensão objetiva da aceleração do ritmo da vida. A primeira consiste em medir o tempo dos episódios ou unidades de ações cotidianas como dormir, comer, falar com a família etc. As pesquisas citadas por Rosa observam que, em média, as pessoas usam menos tempo para comer, dormir, comunicar-se com a família, encontros com amigos, entre outras atividades. Da mesma maneira, a segunda referência empírica consiste na compreensão de ações e experiências: o que se faz ou experimenta em um mesmo intervalo de tempo. Desta forma encurtam-se as pausas e lapsos entre atividades, ou realizam-se várias coisas ao mesmo tempo (multitasking).

A respeito dessas formas de aceleração, Rosa esclarece que elas não estão vinculadas entre si nem pela lógica nem pela causalidade. Isso significa que uma aceleração não determina causal e mecanicamente a outra. Porém, estas possuem efeitos de interconexão que nosso autor propõe analisar em termos de ciclos. Portanto, a análise poderia realizar-se a partir de qualquer ponto do ciclo. Devido a uma motivação heurística, Rosa escolhe partir da relação entre a aceleração tecnológica e a do ritmo da vida. Tal como é feito por outra literatura, neste entrecruzamento é identificada por Rosa uma relação que, a princípio, poderia ser qualificada como paradoxal, mas que é resolvida na medida em que se propõe uma explicação para esta. Em primeiro lugar, é certo que a aceleração tecnológica produz uma liberação do tempo - ou seja, ao liberar tempo de atividades produtivas ou necessárias, aumenta o tempo livre. Isso conduz a reflexões em duas direções: otimistas e pessimistas. Por um lado, leva a um diagnóstico voltado para uma espécie de sociedade harmônica (arcadian-utopian society) ${ }^{24}$, onde, a princípio, seria possível o desfrute de uma enorme quantidade de tempo livre, em outras palavras, a possibilidade da superação do reino da necessidade, como diria Marx, só que desta vez no coração da sociedade capitalista. No nível estrutural, somente uma ética de trabalho, ou uma distribuição injusta dele _ como disse Russell _ ou bem um caráter que favorece o excesso de

\footnotetext{
${ }^{24}$ Rosa cita como fontes Ludwig Erhard, Staffan Linder e Betrand Russell. Rosa, Beschleunigung.
} 
trabalho poderiam barrar o desfrute dessa possibilidade que já estava presente em todas as sociedades modernas. No entanto, pelo lado contrário, o do pessimismo, o fenômeno do desenvolvimento tecnológico também conduz ao medo acerca das consequências do excesso de tempo livre; uma preocupação sobre o uso do tempo excedente e não produtivo; temores fundados em uma ética do trabalho e muitas vezes amparados por uma religião.

O ponto aqui é que, em uma segunda instância, essa liberação de tempo constitui uma condição necessária para desacelerar substantivamente o ritmo de vida, pelo que caberia, a princípio, aguardar esse efeito. Em contraste com essa expectativa, a terceira instância observa, mediante estudos empíricos, que as pessoas se sentem mais estressadas e com uma forte sensação de falta de tempo. Sendo assim, os estudos empíricos que investigam as percepções subjetivas do tempo são de fato fundamentais. Com base nessas referências, primeiro é necessário conferir se a aceleração tecnológica tem liberado o tempo como era esperado e se, de fato, houve diminuição do trabalho. Os estudos empíricos são cruciais, e estes mostram que, realmente, as jornadas laborais e os trabalhos não-remunerados têm reduzido os seus tempos no decorrer dos últimos anos, quer dizer, que a aceleração tecnológica tem cumprido a sua tarefa. Há evidência concreta na interpretação dos dados relativos às horas dedicadas ao trabalho; e a problemática de Rosa não é a questão da injustiça (diferenças de gênero, classe, idade e seus entrecruzamentos), senão que, de fato, a quantidade de horas tenha sido reduzida.

A constatação anterior leva naturalmente à suspeita da percepção dos indivíduos. O tempo liberado é efetiva e objetivamente maior; no entanto, subjetivamente as pessoas se sentem sob estresse e com falta de tempo. Portanto, deve haver um problema na percepção; uma forma inexplicável de irracionalidade, no sentido em que há um descompasso entre percepção e realidade objetiva. Rosa não acredita nesta trilha interpretativa e, ao contrário, confere credibilidade à percepção dos atores; ou seja, deve haver uma dimensão objetiva - distinta da quantidade de tempo livre (no sentido de tempo liberado) - que esteja na base dessas interpretações subjetivas. O problema é constatar isso aqui. Como disse Rosa, o estresse e a sensação de falta de tempo são indicadores subjetivos da aceleração do ritmo de vida. Portanto, o problema não é o "por quê", já que, apesar da liberação de tempo, há persistência desses 
indicadores. Mais do que isso, agora o problema expressa-se na seguinte pergunta: por que há aceleração do ritmo da vida?

Abro aqui um breve parêntese. Este é o ponto em que com maior clareza se evidencia que o problema não é a quantidade de tempo livre como recurso, mas sim a aceleração do ritmo da vida, dimensão analítica que sobrepõe aspectos relacionados, tais como tempo de trabalho (remunerado e não-remunerado) e tempo livre ${ }^{25}$. O hiperativismo do indivíduo torna menos relevante essa distinção. Os mais ativos no tempo de trabalho também tendem a ser mais ativos no tempo livre. Com isso se evidencia a diferença entre a perspectiva dos estudos críticos da sociologia do tempo baseada em pesquisas sobre o uso do tempo (cujo referente normativo para a identificação de injustiças temporais entre grupos é a quantidade de tempo livre e disponível) e a sociologia crítica de Rosa, que, com menor possibilidade de ancorar-se no dado empírico, coloca a ênfase no fenômeno da aceleração, suas causas e consequências.

Volto aqui para a pergunta mencionada acima. Para respondê-la, mantém-se como referência a aceleração tecnológica. Em tal contexto, Rosa indica que essa aceleração se dá graças às inovações tecnológicas; a propósito destas é que cresce a quantidade de ações que demandam recursos importantes de tempo, acima de qualquer ganho de tempo produzido pelos mesmos avanços. Ao contrário, a não falta de tempo se produz quando a taxa de aceleração tecnológica se encontra acima da taxa de crescimento de ações e seu correspondente requerimento de tempo ${ }^{26}$. Contudo, esse crescimento das ações e do tempo investido nelas, mesmo que acima da taxa de aceleração tecnológica, não significa em si uma aceleração do ritmo de vida. Neste sentido, cabe ressaltar que o ponto assumido pelo autor é que o indivíduo busca compensar a escassez de tempo gerada, seja reduzindo os tempos de descanso ou as pausas, seja

\footnotetext{
${ }^{25}$ Rosa acena em Beschleunigung à redução da jornada de trabalho, que sob condições capitalistas de produção estaria associada de maneira inversamente proporcional ao ritmo da vida: quanto mais reduzida a jornada, maior se torna a aceleração do ritmo da vida (incremento de ações por unidade de tempo se encurtam, intensificam e aparece o multitasking). Ao contrário, o tempo livre não tem relação alguma com essa aceleração: quer dizer, o ritmo da vida pode acelerar ou desacelerar independentemente da quantidade de tempo livre. Empiricamente, Rosa disse que há evidência do primeiro dito neste rodapé.

${ }^{26}$ Apresentam-se três possibilidades de análise: a desaceleração do ritmo de vida teria lugar sempre e quando a aceleração tecnológica seja maior do que o crescimento (por exemplo, que seja possível viajar três vezes mais rápido, mas que as viagens sejam realizadas em igual número ou somente duas vezes a mais); ao contrário, quando aceleração tecnológica e taxa de crescimento se equivalem, é possível que o ritmo de vida permaneça sem alteração; por fim, a aceleração do ritmo de vida se produz quando as taxas de crescimento ultrapassam as da aceleração tecnológica. Rosa, Beschleunigung und Entfremdung.
} 
realizando várias tarefas ao mesmo tempo; quer dizer, acelerando o ritmo de vida de forma objetiva. A perspectiva tratada, mais uma vez, não está no maior uso de tempo para uma atividade (neste caso, possibilitado por alguma inovação tecnológica), mas sim nos efeitos que a aceleração acarreta.

A aceleração tecnológica não gera o efeito esperado porque não cumpre com a suposição sobre a qual foi construída na expectativa a respeito desse efeito acontecer, quer dizer, que não tenha lugar o crescimento das atividades e processos que demandem quantidades importantes de tempo. Tal crescimento temporal de fato acontece, a pergunta é por quê: por que ocorre que, diante de opções, possibilidades e contingências, as pessoas reagem esgotando e assumindo as mesmas envolvidas? Por que se se viaja por três vezes mais tempo do que quando a velocidade de deslocamento era apenas a metade? Por que foge das mãos a quantidade de tempo gasto em comunicação por e-mail ou Whatsapp, mídias sociais e internet em geral, gerando assim um déficit temporal que deve ser intercambiado por maior aceleração?

Aqui deve ressaltar-se que a perspectiva de Rosa se encontra distante de qualquer determinismo ou causalismo simples. Para Rosa, os avanços tecnológicos não determinam as ações e os comportamentos, nem o mencionado crescimento. Com efeito, a pergunta de Rosa, neste ponto fundamental, refere-se a quais são as causas desse crescimento e do comportamento específico das pessoas nas sociedades da modernidade tardia. Desta forma, encontram-se três respostas que, embora empiricamente conectadas, são analiticamente independentes entre si.

A primeira delas se refere à competição em todos os âmbitos, ou seja, bem além da esfera da economia capitalista. Nas sociedades modernas, competir é o modo universal e legítimo de designação de status, papeis e mobilidade social; trata-se de uma lógica generalizada, de sentido em que nossa postura nas sociedades modernas está associada (no sentido normativo) ao sucesso e não a formas de atribuição, como era o caso nas sociedades estamentais. Assim se definem a economia capitalista e os esportes, assim é também definida - mesmo que muitas vezes de maneira pouco explícita e menos compulsiva - uma grande parte das relações sociais: para ascender e/ou manter-se na mesma posição, é necessário competir incessantemente. Assim, a competição se apresenta ao indivíduo como uma força social externa, implacável e diante da qual a única alternativa (para quem a tiver) seria renunciar à vida moderna. 
A lógica da competição não é a única lógica característica da modernidade, mas ela constitui um dos motores principais do crescimento e, em consequência, também da aceleração. Além do mais, Rosa identifica a generalização de um imaginário ou ideal de vida segundo o qual uma vida plena seria aquela repleta de experiências e com o máximo de capacidades desenvolvidas e opções aproveitadas. As experiências possíveis e as opções ofertadas são infinitamente maiores do que as possibilidades que um indivíduo tem de realizá-las ao longo da sua vida. Desta forma, há um esforço constante por preencher essa brecha produzida pela aceleração do ritmo de vida, mesmo porque ela se apresenta como a própria solução para viver mais em menos tempo e multiplicar o número de experiências possíveis no mesmo período vital. Sendo assim, essa distância ou brecha alarga-se cada vez mais, e o esforço por encerrá-la torna-se eterno.

Além das duas forças externas mencionadas, acrescenta-se aquilo que Rosa identifica como um sistema autonomizado e que se propulsiona a si mesmo. Há um entrelaçamento entre as três formas de aceleração identificadas por ele - tecnológica, mudança social e ritmo da vida -; estas configuram um sistema que se alimenta e propulsiona a si mesmo. Concentro-me aqui no ponto relativo ao ritmo da vida. Como sabemos, a aceleração não consegue produzir mais tempo livre devido à aceleração do ritmo da vida. Por sua vez, não se pode desprezar que boa parte da aceleração tecnológica é uma resposta a esta última aceleração. A aceleração tecnológica e a aceleração da mudança social geram pressão sobre os indivíduos no sentido de que estes precisam continuar rapidamente o ritmo das mudanças tecnológicas e sociais, questão que por si só custa uma importante aceleração no ritmo de vida. A dinamização da mudança social por meio da competição se traduz para o indivíduo em um "escorregadio desnível” (Max Weber), onde parar ou não se atualizar é ficar para atrás. Nesta lógica, a mesma aceleração tecnológica orientada a poupar tempo teria feito explodir as opções oferecidas pelo mundo globalizado. Enfim, para não perder opções valiosas, incrementam-se as ações por unidade de tempo (aceleração do ritmo da vida), ainda que, ao acontecer sob condições de mudanças sociais aceleradas, se obscurece a visão sobre quais opções podem ser valiosas e quais não. 


\section{Aceleração do ritmo da vida e alienação como bloqueio da ressonância}

Rosa pretende levar tudo o que foi anteriormente dito além da mera descrição e abordar a pergunta: por que seria eticamente criticável o processo da aceleração $?^{27}$ Este seria o ponto em que a perspectiva de Rosa se diferencia da maior parte das outras, já que existem poucos estudos sobre o tempo e temporalidade e estes carecem de uma perspectiva ética e normativa. Tal enfoque é baseado de modo fundamental na denúncia das consequências negativas da aceleração social de caráter totalitário que, em duplo sentido, envolve cada vez mais indivíduos e âmbitos de ação.

Essas consequências podem ser divididas em dois âmbitos. Em um primeiro tipo de ordem sistêmica, elas se expressam nos problemas de sincronização gerados dentro de um ordenamento democrático de direito que, operando na temporalidade, constitui um limite para a aceleração. Já no outro âmbito, são encontradas as consequências sobre a subjetividade, sendo essas as que mais interessam. Existem ao menos duas perspectivas sobre este tipo de consequências de um hiperativismo compulsivo no nível da subjetividade. Um exemplo da primeira perspectiva é a tematização dos limites que este processo encontra em nossa constituição psicofísica e suas consequências - esgotamento das energias psíquicas do sujeito (burnout) - quando transgredidos. O fato de que a administração temporal recai no sujeito e não nas instituições, que ele busque não perder oportunidades valiosas e que ele esteja obrigado a estar atualizado etc., são argumentos que se direcionam para mostrar as consequências do cansaço generalizado do sujeito moderno, cujos indicadores são, entre outros, o burnout e o uso de psicofármacos.

\footnotetext{
${ }^{27}$ Trata-se de um gesto próprio da teoria crítica frankfurtiana. Por exemplo, Habermas devia responder a pergunta de por que resultava criticável a mercantilização do mundo da vida; para isso, ele tinha que ir além do diagnóstico da colonização para demonstrar, em perspectiva antropológica, que tal processo enfraquece as capacidades que nos fazem humanos. Conferir Mauro Basaure, "Continuity through rupture with the Frankfurt school: Axel Honneth's theory of recognition", em Routledge International Handbook of Contemporary Social and Political Theory, 99-109 (New York: Routledge, 2011). Por meio de uma estratégia semelhante, Rosa traduz as consequências da aceleração social como uma distorcida e alienante relação nossa com o mundo. Na aceleração se oculta algo bem mais sério do que o fato de não ter tempo; se esconde uma transformação da própria subjetividade.
} 
Para este artigo, a segunda perspectiva - ancorada num nível mais profundo que o dos efeitos patológicos individuais - é a mais importante. Baseado na tese da aceleração do ritmo de vida, Rosa avança uma análise sobre a contradição entre discurso e ação, no sentido de que o que é expressado discursivamente como desejável ou valioso não é coerente com a ordem do que realmente se faz ou é feito. Se em seu livro Aceleração o conceito de alienação já estava presente, este torna-se central no livro Ressonância. Neste último, o fenômeno empírico, retomado por Rosa, e que vale destacar aqui, é uma discrepância dramática entre, por uma parte, as orientações normativas dos atores (nível discursivo) e por outra, as suas ações. Rosa pergunta-se: por que as pessoas trairiam as suas convicções com os fatos? Será que se trata de simples hipocrisia, de modo que as convicções e valores declarados são apenas uma fantasia justificadora (aquilo em que se realmente acredita é o que se faz, e o que se diz é somente aparência)? Será - o autor continua perguntando-se - que se trata de um autoengano segundo o qual os próprios sujeitos têm ideais de conduta puramente abstratos, de modo que o agir cotidiano seria governado apenas por preferências banais, como o mero conforto e a falta de vontade para realizar ações que atinjam tais ideais?

Rosa rejeita e qualifica como inadequadas tais perspectivas céticas acerca das afirmações normativas dos indivíduos. Tal como fez a respeito das percepções dos atores que se sentiram sob pressão da escassez de tempo - embora tivessem mais tempo livre -, mais uma vez o autor dá crédito aos próprios indivíduos, assumindo uma perspectiva fenomenológica e dando destaque à experiência. Este é o pano de fundo a partir do qual Rosa confere um significado concreto à noção de 'ressonância': entende-se como tal que o agir tem sentido para o sujeito por estar em concordância com suas convicções e valorações. Deixando reconhecer sua dívida intelectual com Charles Taylor, Rosa assume que essas convicções e orientações de valor ou normativas são realmente sentidas pelos sujeitos, tanto que, quando conseguem realizá-las no próprio agir, sentem verdadeira satisfação e até declaram ser felizes. Taylor é chave na formação de Rosa, e, de certa forma, a questão da temporalidade foi uma resposta à pergunta sobre como conduzimos as nossas vidas sob as condições atuais. Neste contexto, compreende-se criticamente que não são 
as nossas "avaliações fortes" o decisivo em nossas vidas ${ }^{28}$, mas sim aquele "dever fazer" urgente que é forçado pelos ritmos temporais que acontecem distantes dos nossos olhos ${ }^{29}$.

Dessa forma, junto com dados e exemplos, Rosa pergunta: por que as atividades e as ações que perpassam a vida cotidiana dos sujeitos não possuem a qualidade de ressonância e, ao contrário, estão em contradição com aquilo que eles consideram como verdadeiramente importante e fonte de satisfação? Por que aquilo que é importante para os sujeitos acaba por ser diluído e impossibilitado no agir cotidiano? Por que há bloqueio da ressonância? Rosa conecta estas perguntas com uma teoria crítica da sociedade que consiste na análise das causas sociais e estruturais das formas de sofrimento social e do fracasso na possibilidade de levar uma vida verdadeira e boa (gutes Leben) ${ }^{30}$. Quando o que se deseja e o que se deve fazer se afastam desse modo, são geradas condições de infelicidade, deixando de ser uma vida boa ${ }^{31}$. Além disso, Rosa também interliga a herança de Taylor no que corresponde às condições para uma identidade pessoal plena ${ }^{32}$.

Seguindo esta perspectiva que valida e qualifica a experiência, Rosa entende por falta de ressonância - alienação - a consequência de dinâmicas objetivas associadas à aceleração do ritmo da vida. Para ele, são os imperativos estruturais da aceleração e do crescimento que permitem compreender melhor o hiato entre valores e ações. Tais imperativos imunizam as ações cotidianas contra as influências dos valores que, a princípio, poderiam afetá-las de maneira bem diferente. Assim, Rosa deu continuidade a uma das suas primeiras críticas ao ideal de sujeito autônomo, característico do liberalismo ${ }^{33}$. Um fazer cotidiano constante, dominado pelos imperativos da otimização, do crescimento e da aceleração, afasta os sujeitos da realização

\footnotetext{
${ }^{28}$ Hartmut Rosa, Identität und kulturelle Praxis: Politische Philosophie nach Charles Taylor (Frankfurt am Main: Campus, 1998).

${ }^{29}$ Hartmut Rosa, "Aceleración, Alienación y Resonancia”, em Investigación y teoría crítica para la sociedad actual, Mauro Basaure y Darío Montero eds. (Barcelona: Editorial Anthropos, 2018).

${ }^{30}$ Ulrich Bröckling. "Der Kopf der Leidenschaft: Soziologie und Kritik", Leviathan 41 (2013): 309-23; Hartmut Rosa, "Capitalism as a Spiral of Dynamisation: Sociology as Social Critique", em Sociology, Capitalism, Critique, Hartmut Rosa, Stephan Lessenich y Klaus Dörre eds., 67-97 (London: Verso, 2015).

${ }^{31}$ Hartmut Rosa, Stephan Lessenich, Margrit Kennedy e Theo Waigel, Weil Kapitalismus sich ändern muss (Wiesbaden: Springer, 2013).

32 Rosa, Identität und kulturelle Praxis; Walter Schaupp, Gerechtigkeit im Horizont des Guten: Fundamentalmoralische Klärungen im Ausgang von Charles Taylor (Freiburg: Freiburg im Breisgau, 2003).

${ }^{33}$ Rosa, "On Defining the Good Life".
} 
prática do que realmente é importante e valorizado, conduzindo-os a ações e relacionamentos insatisfatórios consigo e com os outros.

Sem pretensão sistemática, menciono alguns raciocínios de Rosa que possibilitam a compreensão do aspecto objetivo que produz tal incoerência. De fato, com a ajuda de Luhmann, nosso autor refere-se à tirania do deadline (prazo final) e aos problemas que encontra o sujeito moderno ao esforçar-se para compatibilizar as exigências temporais que surgem dos diferentes sistemas em que está inserido. Sempre há um custo nesse esforço, expressado no adiamento de outros âmbitos considerados relevantes, como a vida familiar ou social. Apesar da satisfação produzida por ela, a vida social é a primeira a ser excluída das possibilidades quando há falta de tempo. Nas pesquisas consultadas, a resposta típica é "não tenho tempo", porém, dada esta perspectiva, não pode ser interpretada como um pretexto. Neste contexto, Rosa tem pesquisado acerca das consequências da diminuição do horizonte de futuro para fenômenos como o engajamento cidadão ${ }^{34}$. A aceleração do ritmo da vida compromete as prioridades até o ponto em que as pessoas possam não se autorrealizar nas suas ações.

Existem condições que levam a privilegiar o curto prazo. Há uma tendência das pessoas pelo imediato ao invés de questões de longo prazo, embora estas últimas possam ser mais satisfatórias. As metas que envolvem uma perspectiva longínqua se perdem por conta da solicitação de respostas ou atenção com aquilo que abre opções ou que permite manter-se atualizado. Neste sentido, devido à desinstitucionalização das biografias, as certezas têm sido perdidas, de modo que a orientação de longo prazo é percibida como menos racional. Como disse Rosa, não é raro que muitas pessoas, sobretudo jovens, tenham dificuldade para imaginar a si mesmas e ao seu futuro.

Ao defender esta perspectiva, Rosa toma como referência as considerações dos próprios atores, busca identificar por que os atores não se realizam em suas ações, aliás, questão que já estava no conceito de alienação de Marx $^{35}$. Como exemplo-chave, Rosa insiste acerca dos relacionamentos afetivos, sejam eles familiares ou de amizade. Em torno dessas relações existem fortes expectativas; ele afirma que elas são um enorme depósito e refúgio de 'ressonância'. Tais

34 Michael Corsten, Michael Kauppert y Hartmut Rosa, Quellen Bürgerschaftlichen Engagements: Die biographische Entwicklung von Wir-Sinn und fokussierten Motiven (Wiesbaden: Verlag für Sozialwissenschaften, 2007).

${ }^{35}$ Christoph Henning, Marx und die Folgen (Stuttgart: Weimar, 2017). 
vínculos não seriam compatíveis (sob pena de graves conflitos e patologias) com práticas de funcionalização orientadas por critérios de eficiência, rendimento e crescimento $^{36}$. Estes relacionamentos têm uma dimensão do "indisponível", no sentido de que não estão à disposição como meios porque o tempo dedicado a eles é um fim em si mesmo. Essas relações apresentam ao mesmo tempo flexibilidade, no sentido de que a quebra de expectativas e conflitos não conduziria diretamente ao término do vínculo, muitas das vezes até o contrário. Assim, essas relações são flexíveis, podem ser adiadas sem prejuízo ou quebra da relação, mesmo se houver quaisquer postergação pelas urgências impostas pelos imperativos cotidianos, sem que isso signifique uma imediata quebra da relação.

Sob estas condições, Rosa refere-se aos bloqueios da ressonância no quadro das relações familiares e de proximidade. Por exemplo, casais novos e com fortes convicções de justiça na distribuição dos afazeres relativos à casa e ao cuidado, podem, após um tempo, adaptar-se e por meio de mudanças voltar-se para as distribuições tradicionais de funções. A relação é flexível para configurar estas ações que contradizem suas convicções. Para Rosa, não se trata nem do patriarcado oculto numa fachada ideológica de igualdade, nem de mero autoengano, mas sim da introdução silenciosa e distante das nossas vistas desses imperativos de crescimento e aceleração, impedindo assim uma configuração saudável das suas relações com as convicções sociais. O mesmo ocorre com os tempos dedicados ao lazer e à educação das crianças; à vida do casal como tal; ao encontro com os amigos; à autorrealização em atividades que produzem prazer, como tocar um instrumento musical etc. Todos esses momentos que não têm limites e nem prazos temporais são adiados com frequência até serem retirados da configuração horária do cotidiano.

Assumindo que esses tempos são realmente importantes e expressam valores relevantes, tais como as relações que supõem expectativas legítimas de comportamento, os indivíduos, tiranizados pelos imperativos de crescimento e aceleração, sentem muito mais do que a simples falta de tempo para o que é mais valorado e importante; além disso, eles vivenciam tais relações com sentimentos de culpa, porque não fazem o que sabem que deveriam fazer - não segundo parâmetros externos, mas de acordo com o que eles mesmo consideram adequado e correto.

\footnotetext{
${ }^{36}$ Luc Boltanski, Robin Celikates e Axel Honneth, "Soziologie der Kritik oder Kritische Theorie? Ein Gespräch mit Robin Celikates", em Was ist Kritik?, Rahel Jaeggi e Tilo Wesche eds., 81-116 (Frankfurt am Main: Suhrkamp, 2009).
} 
Desta maneira, isso torna pertinente o vínculo entre a teoria crítica de Rosa e as análises empíricas sobre tópicos que, seja mediante técnicas quantitativas e/ou qualitativas, debem ser aprofundados: relação entre o que os sujeitos fazem e o que desejam fazer; qual é a relação entre estes desejos e seus valores e como avaliar a brecha entre o agir e o desejo.

\section{Conclusões}

A obra de Rosa, em grande parte, deixa reconstruir-se nos termos de uma busca das causas da aceleração, da clarificação fenomenológica desse fenômeno, assim como da análise crítica das suas consequências. Seguindo a lógica antecedentes-fenômeno-consequências, neste artigo procurei delimitar e reconstruir, em primeiro lugar, o alcance do diagnóstico de época baseado no fenômeno da aceleração. Em segundo lugar, dediquei-me a reconstruir a clarificação fenomenológica de tal fenômeno, centrando-me em uma das suas dimensões: a aceleração do ritmo da vida. Foi nesse contexto que identifiquei a diferença da sociologia crítica de Rosa em relação àquela embasada nos estudos sobre o tempo.

Essa reconstrução e clarificação conduz à questão dos precedentes ou causas da aceleração. Uma destas - enfatizada por Rosa - é a lógica do crescimento das ações. As causas desse crescimento são: a concorrência; a promessa de uma vida repleta de experiências; e uma espécie de automatização e uma autopropulsão da aceleração por meio da retroalimentação das suas formas tecnológicas, das mudanças sociais e do próprio ritmo de vida. Uma parte importante das últimas propostas de Rosa pode ser entendida como um esforço por encontrar precedentes de um processo autonomizado e descontrolado da aceleração social, do crescimento e da inovação ${ }^{37}$, daí que o autor realize uma proposta não economicista de análise e crítica do capitalismo na modernidade $\operatorname{tardia}^{38}$.

Entretanto, neste artigo foquei-me nas consequências da aceleração social, sobretudo naquela que Rosa concebe como uma condicionante dos bloqueios da ressonância ou da alienação. Quer dizer, a discrepância entre as orientações de valor e as ações reais. Tal

\footnotetext{
${ }^{37}$ Rosa, Unverfügbarkeit.

${ }^{38}$ Hartmut Rosa, Stephan Lessenich, Margrit Kennedy e Theo Waigel, Weil Kapitalismus sich ändern muss (Wiesbaden: Springer, 2013).
} 
discrepância ou autotraição parece-me um fenômeno relevante porque permite juntar à análise empírica uma robusta perspectiva da teoria crítica. Desta forma, adquirem relevância perguntas como: Por que as pessoas fazem coisas que não desejam fazer, que não coincidem com suas orientações de valor? Por que desejariam dedicar maior tempo a coisas às quais já dedicam tempo, mas que não parece ser suficiente? Por que é quase impossível dedicar tempo a atividades que constituem o cerne vocacional da profissão para a qual se estudou ou na qual se formou? Portanto, vale a pena continuar investigando esse tipo de problemática nos campos teórico e empírico $^{39}$, pois tal pesquisa poderia tornar possível uma conexão, sistemática e pertinente, do estudo das patologias sociais do tempo e da aceleração com questões relativas às injustiças, sobretudo as de classe e de gênero.

\section{Agradecimentos}

Proyeto Fondecyt Regular 1191490, "Desigualdad Temporal, Reproducción y Exclusión Social”; Proyecto Fondecyt Regular 1200493, “Capitalismo y legitimación de la democracia: el circuito global-local de producción de ideas a partir de la plataforma Project Syndicate"; e FONDAP 15130009, Centro de Estudios de Conflicto y Cohesión Social, COES.

Tradução do espanhol por Carlos Vidal e Celeste Farias.

39 No Proyecto Fondecyt 1191490, Desigualdad Temporal, Reproducción y Exclusión Social, trabalham comigo, Maya Zilveti, Martina Yopo, Pedro Güell, Camilo Vera e Andrés Díaz, encontramos-nos, especificamente, fazendo investigações nestas áreas de pesquisas. 


\section{Referências bibliográficas}

Basaure, Mauro. "Continuity through rupture with the Frankfurt school: Axel Honneth's theory of recognition". Em Routledge International Handbook of Contemporary Social and Political Theory, 99-109. New York: Routledge, 2011.

Beuthan, Ralf. "Media and Time”. Em Encyclopedia of Time: Science, Philosophy, Theology, \& Culture, H. James Birx editor, 832-41. Los Angeles: SAGE Publications, 2009.

Boltanski, Luc, Robin Celikates y Axel Honneth. "Soziologie der Kritik oder Kritische Theorie? Ein Gespräch mit Robin Celikates". Em Was ist Kritik?, Rahel Jaeggi e Tilo Wesche editores, 81-116. Frankfurt am Main: Suhrkamp, 2009.

Boltanski, Luc e Arnaud Esquerre. Enrichissement. Une critique de la marchandise. Paris: Gallimard, 2017.

Bröckling, Ulrich. "Der Kopf der Leidenschaft: Soziologie und Kritik”. Leviathan 41 (2013): 309-23.

Corsten, Michael, Michael Kauppert e Hartmut Rosa. Quellen Bürgerschaftlichen Engagements: Die biographische Entwicklung von Wir-Sinn und fokussierten Motiven. Wiesbaden: Verlag für Sozialwissenschaften, 2007.

Henning, Christoph. Marx und die Folgen. Stuttgart: Weimar, 2017.

Honneth, Axel. "Umverteilung als Anerkennung. Eine Erwiderung auf Nancy Fraser". Em Umverteilung oder Anerkennung? Eine politisch-philosophische Kontroverse, 129-224. Frankfurt am Main: Suhrkamp, 2003.

Leccardi, Carmen. "Resisting 'Acceleration Society"”. Constellations 10 (2003): 34-41.

Linder, Staffan Burenstam. The Harried Leisure Class. New York: Columbia University Press, 1970.

Rosa, Hartmut. Identität und kulturelle Praxis: Politische Philosophie nach Charles Taylor. Frankfurt am Main: Campus, 1998.

-----. “On Defining the Good Life: Liberal Freedom and Capitalist Necessity”. Constellations 5 (1998): 201-14. 
-----. Beschleunigung: Die Veränderung der Zeitstrukturen in der Moderne: 1760. Frankfurt am Main: Suhrkamp, 2005.

-----. "Von der stabilen Position zur dynamischen Performanz Beschleunigung und Anerkennung in der Spätmoderne”. Em Sozialphilosophie und Kritik, Rainer Forst, Martin Hartmann, Rahel Jaeggi e Martin Saar editores, 655-71. Frankfurt am Main: Suhrkamp, 2009.

-----. Beschleunigung und Entfremdung: Entwurf einer kritischen Theorie spätmoderner Zeitlichkeit. Berlin: Suhrkamp, 2013.

----. "Capitalism as a Spiral of Dynamisation: Sociology as Social Critique”. Em Sociology, Capitalism, Critique, Hartmut Rosa, Stephan Lessenich e Klaus Dörre editores, 67-97. London: Verso, 2015.

-----. Beschleunigung: Die Veränderung der Zeitstrukturen in der Moderne. Frankfurt am Main: Suhrkamp, 2017.

-----. “(Parity of) Participation-The Missing Link Between Resources and Resonance”. Em Feminism, Capitalism, and Critique: Essays in Honor of Nancy Fraser, Banu Bargu e Chiara Bottici editores, 157-66. New York: Palgrave Macmillian, 2017.

-----. “Aceleración, Alienación y Resonancia”. Em Investigación y teoría crítica para la sociedad actual, Mauro Basaure e Darío Montero editores. Barcelona: Editorial Anthropos , 2018.

-----. Resonanz: Eine Soziologie der Weltbeziehung. Berlin: Suhrkamp, 2018.

-----. Unverfügbarkeit. Salzburg: Residenz, 2018.

-----. “'Spirituelle Abhängigkeitserklärung'. Die Idee des Mediopassiv als Ausgangspunkt einer radikalen Transformation". Em Große Transformation? Zur Zukunft moderner Gesellschaften: Sonderband des Berliner Journals für Soziologiei, Klaus Dörre, Hartmut Rosa, Karina Becker, Sophie Bose e Benjamin Seyd editores, 35-56. Wiesbaden: VS Verlag für Sozialwissenschaften, 2019.

Rosa, Hartmut, Stephan Lessenich, Margrit Kennedy e Theo Waigel. Weil Kapitalismus sich ändern muss. Wiesbaden: Springer, 2013.

Rosa, Hartmut e William e Scheuerman editores. High-Speed Society: Social Acceleration, Power, and Modernity. Pennsylvania: Pennsylvania State University Press, 2010. 
Rosa, Hartmut, David Strecker e Andrea Kottmann. Soziologische Theorien. Stuttgart: UTB Basics, 2018.

Schaupp, Walter. Gerechtigkeit im Horizont des Guten: Fundamentalmoralische Klärungen im Ausgang von Charles Taylor. Freiburg: Freiburg im Breisgau, 2003.

Ulferts, Heike, Christian Korunka y Bettina Kubicek. "Acceleration in working life: An empirical test of a sociological framework". Time \& Society 22 (2013): 161-185.

\section{Sobre o autor}

Mauro Basaure. Professor do Quadro de Sociologia na Universidade Andrés Bello em Chile (Santiago, Chile). Diretor do Programa de Doutorado em Teoria Crítica e Sociedade atual nesta mesma casa de estudos superiores. É pesquisador do "Centro de Estudios de Conflicto y Cohesión Social" COES e membro do conselho de Doutorado em Sociologia da Universidade Alberto Hurtado. Doutor em Filosofia pela Universidade Johann Wolfgang Goethe em Frankfurt, na Alemanha. Mestre em Filosofia Política e Sociólogo da Universidade de Chile. Foi pesquisador convidado na Universidade Livre em Berlim, na Universidade de Humboldt, na Escola de Altos Estudos em Ciências Sociais de Paris, no Instituto para a Investigação Social de Frankfurt e no Colégio Max Weber da Universidade de Erfurt. Autor de vários livros e artigos na área da teoria social e política contemporânea. Correio eletrônico: mauro.basaure@gmail.com. 